\title{
Development of a Vibratory Roller with Automatic Compaction Data Processing Functions
}

\author{
H.Fujikawa ${ }^{a}$, T.Kiriyama ${ }^{b}$, M.Fukuda ${ }^{c}$, N.Inaba ${ }^{d}$ \\ a Kawasaki Heavy Industries, Ltd., 2680 Oka, Inami-cho, Kako-gun, Hyogo Pref., 675-11 \\ JAPAN \\ b Public Works Research Institute, Ministry of Construction, 1 Asahi, Tsukuba-si, Ibaraki \\ Pref., 305 JAPAN \\ c Advanced Construction Technology Center, Otowa NS Bldg., 2-10-2 Otowa, Bunkyo-ku, \\ Tokyo, 112 JAPAN \\ d Nippon Hodo Co., Ltd., 6-70 Mihashi, Omiya-si, Saitama Pref., 331 JAPAN
}

\begin{abstract}
This is a vibratory roller with an automatic compaction data processing functions capable of performing compaction work by monitoring the compaction degree in a nondestructive method. The roller is equipped on its main body with a travel-type RI sensor to measure density in real time and sensors to measure the position of the vehicle itself and a control system. The development of this system has made it possible to show to the operator the status of compaction in progress in the form of a compaction map so that he may perform roller compaction as he confirms the status of the work. The final compaction data will be stored in IC cards so that they may be used for field operation control and as inspection data. The development of this product has been carried out as a part of the overall technological development project "Development of New Working Technology in Construction Industries" of the Ministry of Construction. The members of this joint development project include, in addition to those shown above, Gaeart Kumagai Co., Ltd., Seiki Tokyu Kogyo Co., Ltd., Toa Doro Kogyo Co., Ltd. and Fieldtech Co., Ltd..
\end{abstract}

\section{INTRODUCTION}

In the conventional compaction method, compaction roller pass number control is adopted wherein the compaction roller is passed a certain number of times as pre-determined empirically to attain the required compaction degree. This kind of method, however, always suffers from insufficient compaction attributable to operator error. Further, measurement of the core density and the sand replacement density is practiced to confirm the compaction degree, but such destructive measurement requires much time and labor. In addition, since the above-mentioned measurement is made after compaction work has been completed, if the measurement results show insufficient compaction, re-compaction work will be necessary, requiring a large amount of time and cost.

The vibratory roller with automatic compaction data processing functions is being developed to solve the above problems and enable even unskilled operators to attain optimum roller compaction by giving real-time compaction data to them and to save the time and expense of the post-compaction field density measurements by making the recorded data available for use in operation control and also for use as inspection data. 


\section{GENERAL DESCRIPTION OF THE SYSTEM}

The configuration of this system is shown in Fig. 1 and Fig. 2.

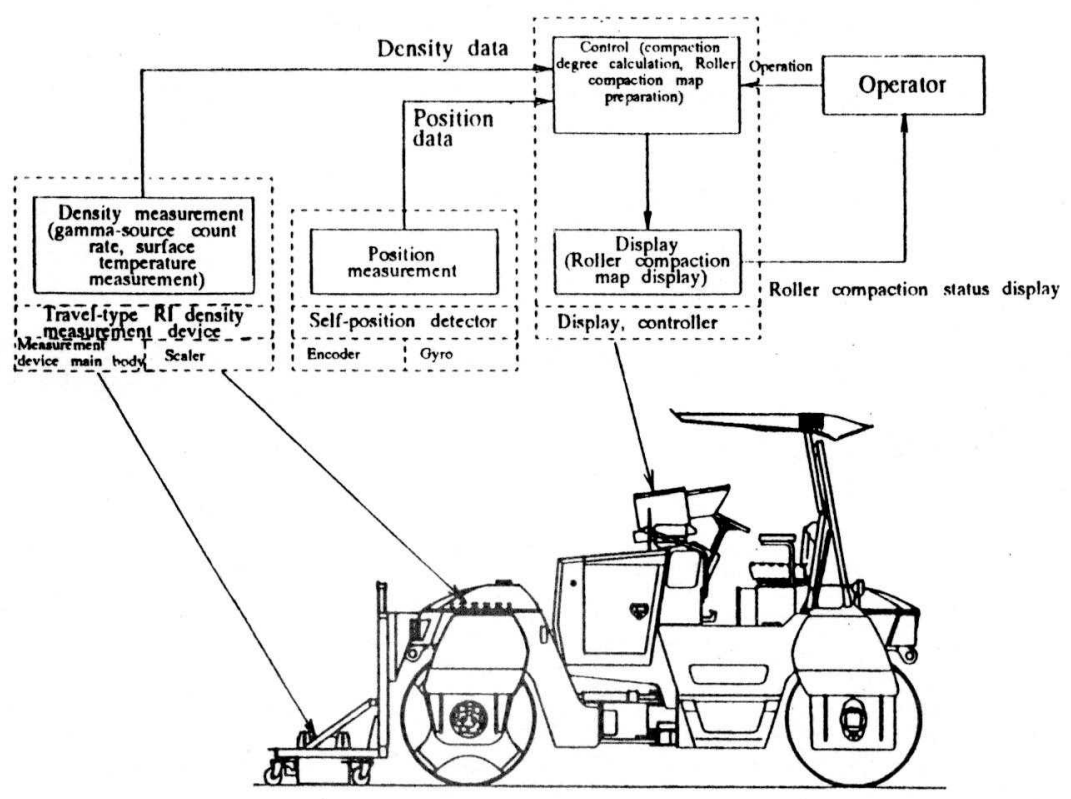

Fig. 1 System outline

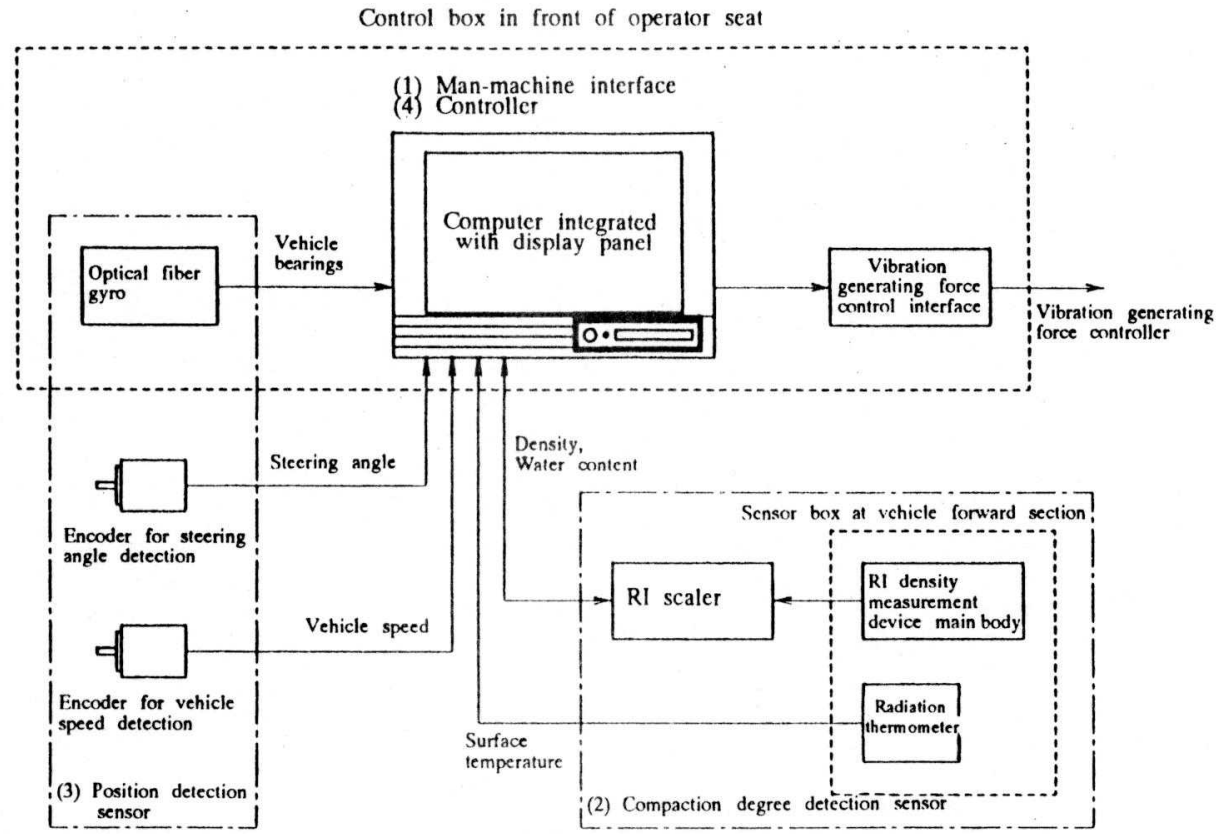

Fig. 2 Composition of measurement control 


\subsection{Roller main body}

The main body is a $7^{\mathrm{T}}$ class vibratory roller commonly used for road pavement, whose basic specifications are as shown in Table 1. This roller is equipped with a continuously variable vibration generation mechanism capable of controlling the compaction force as shown in Fig. 3.

Table 1 Vibratory roller basic specifications

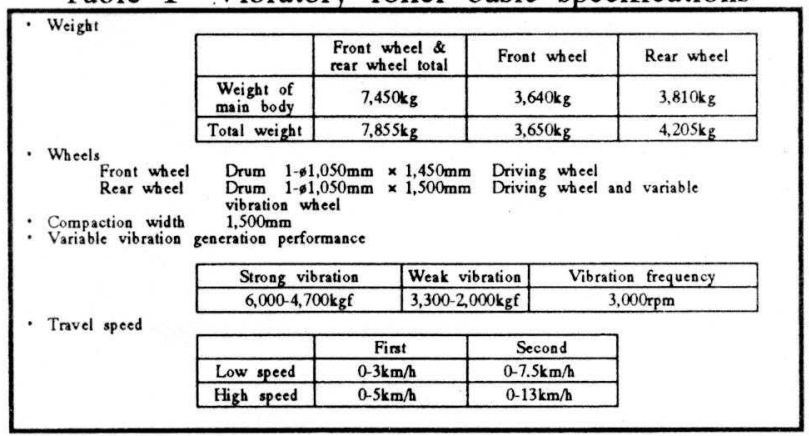

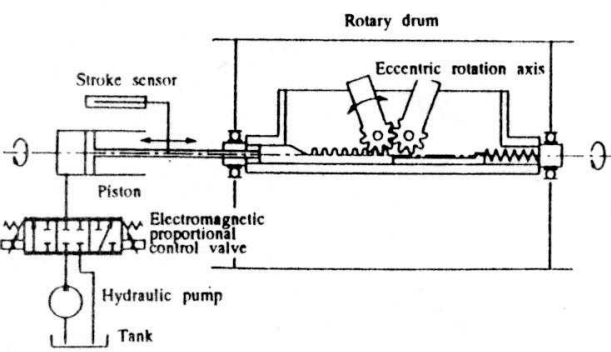

Fig. 3 Variable vibration generation mechanism

\subsection{Density measurement device (Travel-type RI density measurement device)}

The main body of the travel-type RI density measurement device is a scattering-type density measuring device using a very weak radioactive isotope (RI) that is not subject to any legal restrictions when used in Japan. In the present project, however, an additional specification for heat-resistance measure is incorporated so that it can be used also in asphalt concrete paving using hot mixture. Photo 1 shows the appearance of the main body of the measurement device, and Table 2 shows its basic specifications.

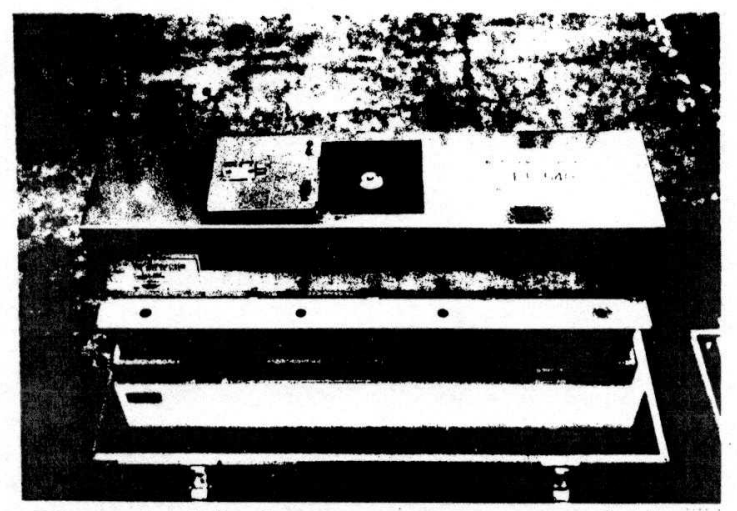

Photo 1 RI density measurement device main body appearance

The main body of this measurement device is, as shown in Fig. 1, housed in the sensor box at the forward section of the vehicle. It can be brought into contact with the ground at the time of measurement and held up with the use of a lift device when no measurement is being made.

Some design considerations are given to this travel-type RI sensor housing device with the lift mechanism so that the travel device wheels do not injure the roller compacted road surface when the vehicle is turned.
Table 2 RI density measurement device specifications

\begin{tabular}{|c|c|c|c|}
\hline $\begin{array}{c}\text { Measuring } \\
\text { method }\end{array}$ & $\begin{array}{l}\text { Wet deasity } \\
\text { Moisture density }\end{array}$ & $\vdots$ & $\begin{array}{l}\text { Gamma source back scattering-type } \\
\text { Neutron source back scattering-type }\end{array}$ \\
\hline $\begin{array}{l}\text { Measurable } \\
\text { range }\end{array}$ & $\begin{array}{l}\text { Wet density } \\
\text { Moisture density }\end{array}$ & $\vdots$ & $\begin{array}{l}1.20-2.5 \mathrm{~g} / \mathrm{cm}^{3} \\
0.05-0.7 \mathrm{~g} / \mathrm{cm}^{3}\end{array}$ \\
\hline $\begin{array}{c}\text { Radiation } \\
\text { source }\end{array}$ & $\begin{array}{l}\text { Gamma source } \\
\text { (Density measurement) } \\
\text { Neutron source } \\
\text { (Water content measureme } \\
\text { - Either of the radiation } \\
\text { stecl capsule and is fu } \\
\text { be the source of rays. }\end{array}$ & $\begin{array}{c}: \\
\vdots \\
\text { ent) } \\
\text { nay } \\
\text { urther }\end{array}$ & 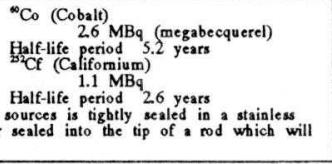 \\
\hline Detectors & $\begin{array}{l}\text { Gamma source } \\
\text { Neutron source }\end{array}$ & $;$ & $\begin{array}{l}\text { Scintillation counter } \\
2 \text { units } \\
\text { 'He (Helium three) tube } \\
2 \text { units }\end{array}$ \\
\hline $\begin{array}{c}\text { Measuring } \\
\text { time }\end{array}$ & 1. 999 seconds & & \\
\hline Display & Count rate & ; & 6-digit 2-channel \\
\hline Printing & Built-in printer & & \\
\hline $\begin{array}{l}\text { Data } \\
\text { recording }\end{array}$ & Memory card writer & & \\
\hline Power source & $\begin{array}{l}\text { Internal power source } \\
\text { Extemal power source }\end{array}$ & ; & 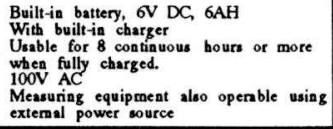 \\
\hline
\end{tabular}


Further considerations are given to maintain the distance between the measurement device main body and the road surface constant as long as possible as such distance affects the accuracy of data.

In addition, a radiation thermometer is provided within said sensor box to measure the surface temperature of the hot mixture.

The control section of the RI density measurement device, by communicating with the RI scaler, is able to control the measurement start time and the measurement sampling time as set by the operator. This control section also computes the density using a conversion formula from the data (gamma-source count rate, etc.) sent from the scaler and calculates the compaction degree with reference to the standard density previously established and input.

\subsection{Self-position detection device}

The self-position detection sensor is composed of an optical fiber gyro that detects the angular velocity of the vehicle rear section (angle determined through integration), an absolute type encoder that measures the articulate angle (steering angle) of the vehicle body and an incremental encoder that is installed on the forward wheel axis to measure the rotation speed of the wheels.

The position of the roller is determined by this self-position detection sensor as follows. (See Fig. 4)

Assuming that the travel direction of the vehicle is the tangential direction of the vehicle body, the $\mathrm{X}$-axis direction component $\mathrm{V}_{\mathrm{X}}$ and the $\mathrm{Y}$-axis direction component $\mathrm{V}_{\mathrm{Y}}$ of the speed $\mathrm{V}$ obtained from the front wheel encoder can be expressed by the following equations:

$$
\begin{aligned}
& V_{\mathrm{X}}=\mathrm{V} \cos \left(\mathrm{S}_{\theta / 2}\right) \cdot \sin \left(\mathrm{G}_{0}+\mathrm{S}_{\theta / 2}\right) \\
& \mathrm{V}_{\mathrm{Y}}=\mathrm{V} \cos \left(\mathrm{S}_{\theta / 2}\right) \cdot \cos \left(\mathrm{G}_{0}+\mathrm{S}_{\theta / 2}\right)
\end{aligned}
$$

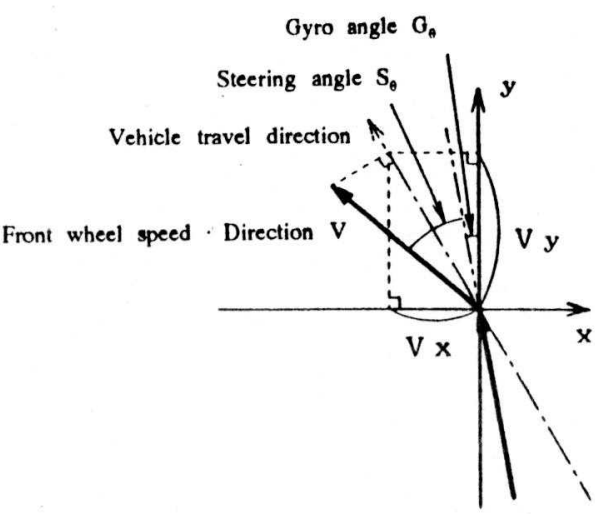

Rear wheel speed Direction

Fig. 4 Self-position calculation method

Further, the position of the vibratory roller is calculated from $\mathrm{V}_{\mathrm{X}}$ and $\mathrm{V}_{\mathrm{Y}}$ as follows: $\mathrm{X}_{\mathrm{n}+1}=\mathrm{X}_{\mathrm{n}}+\mathrm{V}_{\mathrm{X}} \cdot \Delta \mathrm{t}$
$\mathrm{Y}_{\mathrm{n}+1}=\mathrm{Y}_{\mathrm{n}}+\mathrm{V}_{\mathrm{Y}} \cdot \Delta \mathrm{t}$

When indicating the self-position obtained by the above formulas on the roller compaction map of the display composed of a group of rectangular grid blocks, the left edge of the measuring section will be travelled before measurement and this travel line will be stored in the computer as the reference line so that winding roads can also be dealt with.

\subsection{Man-machine interface section}

The man-machine interface software processes the data from the sensors, displays the roller compaction map on the screen, and stores the data in IC cards. A dialogue method using touch keys on the indication screen is employed to enable operation by operators without computer knowledge. The screen shows only those items which can be set and operated at that point of time.

The calculated compaction degree will be displayed on the screen in three (3) different colors depending on the compaction degree. Fig. 5 shows an example of such roller compaction map.

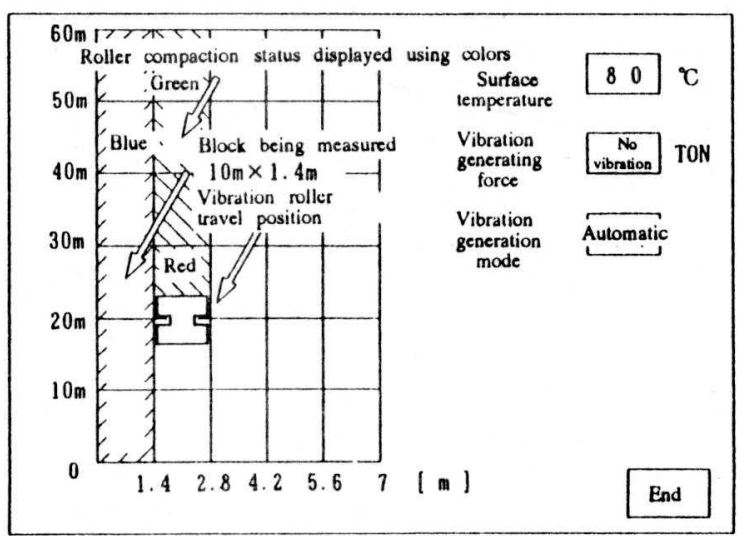

Fig. 5 Compaction status screen display 


\section{BASIC OPERATIONOF THE SYSTEM}

Fig. 6 shows the flowchart of the operation.

(1) Measurement of the measured data correction radiation dose

The correction conditions will be determined by measuring the change in the source of radiation with age to enable highaccuracy measurements.

(2) Computer actuation

The control system power source is turned on to prepare for measurement.

(3) Input of the measurement conditions In addition to the correction conditions of (1) above, additional measurement conditions such as the type of material and sampling time are input and set.

(4) Reference line establishment

Before the roller compaction map is displayed on the rectangular screen, the left edge of the road is travelled to establish the reference line.

(5) Data measurement

Roller compaction work and data measurement are performed.

(6) Data storage (IC card)

When the measurement has been completed and "End" is input, the measurement data are stored in the IC card. Table 3 shows an example of measurement data output.

\section{TEST OPERATION RESULTS}

As of the end of 1995, three (3) test operations, as shown in Table 4, have been performed.

\begin{tabular}{|c|l|cc|}
\hline \multicolumn{3}{|c|}{ Table 4 } & \multicolumn{1}{|c|}{ Test operations performed } \\
\hline Year/Month & \multicolumn{1}{|c|}{ Location } & \multicolumn{1}{c|}{ Type of work } \\
\hline Nov. 1994 & $\begin{array}{l}\text { National Route 51 in } \\
\text { Ibaraki Pref. }\end{array}$ & $\begin{array}{c}\text { Base course } \\
\text { (Crushed stone for mechanical } \\
\text { stabilization. Bituminous } \\
\text { stabilization) }\end{array}$ & $\begin{array}{c}\text { Binder course } \\
\text { (Coarse-graded asphalt } \\
\text { concrete) }\end{array}$ \\
\hline June 1995 & $\begin{array}{l}\text { New National Route 4 in } \\
\text { Tochigi Pref. }\end{array}$ & $\begin{array}{l}\text { Base course } \\
\text { (Bituminous stabilization) }\end{array}$ \\
\hline Oct. 1995 & $\begin{array}{l}\text { National Route 116 in } \\
\text { Niigata Pref. }\end{array}$ & $\begin{array}{c}\text { Binder course } \\
\text { (Coarse-graded asphalt concrete) }\end{array}$ \\
\hline
\end{tabular}

Fig. 6 Operation flowchart

Table 3 Example of measurement data output

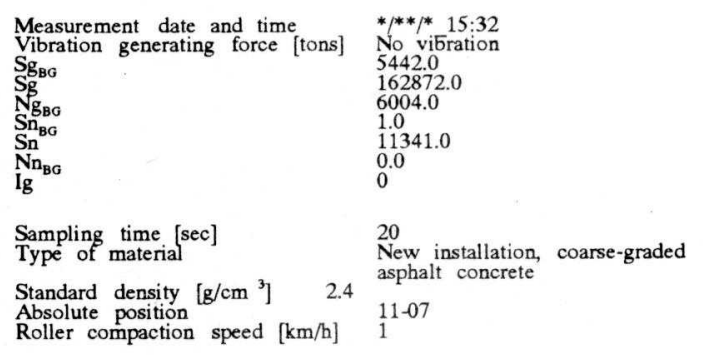

\begin{tabular}{|c|c|c|c|c|c|}
\hline$x$ & $\mathrm{Y}$ & No. of roller & $\begin{array}{c}\text { Compaction } \\
\text { degree }\end{array}$ & $\begin{array}{l}\text { Water } \\
\text { conntent }\end{array}$ & $\begin{array}{c}\text { Surface } \\
\text { temperature }\end{array}$ \\
\hline $\begin{array}{l}0 \\
0 \\
1 \\
1 \\
2 \\
2\end{array}$ & $\begin{array}{l}0 \\
1 \\
0 \\
1 \\
0 \\
1\end{array}$ & $\begin{array}{l}\overline{2} \\
\frac{1}{2}\end{array}$ & $\begin{array}{l}92.7 \\
87.2 \\
92.3 \\
98.5 \\
99.2 \\
97.8\end{array}$ & $\begin{array}{l}3.3 \\
3.7 \\
3.2 \\
3.5 \\
3.0 \\
3.5\end{array}$ & $\begin{array}{l}57.0 \\
500.8 \\
50.8 \\
51.6 \\
50.8 \\
42.5\end{array}$ \\
\hline
\end{tabular}


Though similar results were obtained as to compaction density level and density dispersion in each case of test operation, two (2) types of work were performed, one involving the crushed stone for mechanical stabilization and the other involving an asphalt mixture. And the results of the operation in Ibaraki Prefecture are given below. Operation at that time is shown in Photo 2.

\subsection{Base course}

(crushed stone for mechanical

stabilization)---See Table 5 and Fig. 7

The density as measured by RI method was slightly less than the field density (sand replacement density). However, dispersion of respective RI measurements was smaller than the dispersion of the field density. It is presumed that if, in the future, the volume of data is increased and count values are corrected continuously so that the RI measurement values are closer to the absolute values of the field density, measurement data of sufficiently high reliability may be obtained.

Table 5 Base course (crushed stone for mechanical stabilization) test Standard density: $2.232 \mathrm{~g} / \mathrm{cm}^{3}$

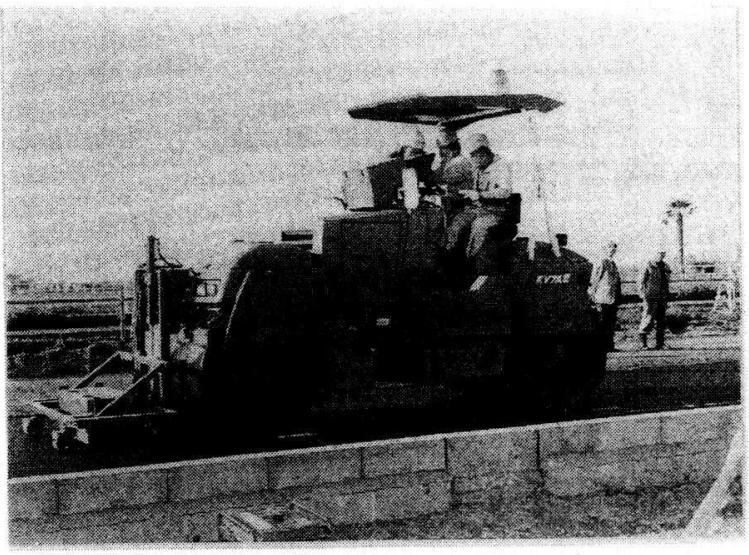

Photo 2 Operation

\begin{tabular}{|c|c|c|c|}
\hline & \multicolumn{3}{|c|}{ Dry density $\rho \mathrm{d}\left(\mathrm{g} / \mathrm{cm}^{3}\right.$ ) } \\
\cline { 2 - 4 } & Travel-type RI & $\begin{array}{c}\text { Stationary-type } \\
\text { RI }\end{array}$ & $\begin{array}{c}\text { Sand replace- } \\
\text { ment } \\
\text { density }\end{array}$ \\
\hline Average value & $\mathbf{2 . 0 9 8}$ & 2.100 & 2.246 \\
\hline Maximum value & $\mathbf{2 . 1 3 8}$ & 2.160 & 2.330 \\
\hline Minimum value & $\mathbf{2 . 0 4 3}$ & 2.029 & 2.101 \\
\hline $\begin{array}{c}\text { Compaction } \\
\text { degree (\%) }\end{array}$ & $\mathbf{9 4 . 0}$ & 94.1 & 100.6 \\
\hline $\begin{array}{c}\text { Standard } \\
\text { deviation }\end{array}$ & $\mathbf{0 . 0 2 4}$ & 0.035 & 0.074 \\
\hline $\begin{array}{c}\text { Coefficient of } \\
\text { variation (\%) }\end{array}$ & 1.14 & 1.67 & 3.32 \\
\hline
\end{tabular}

Fig. 7 Comparison between field density and travel-type and stationarytype RI density measurement results

(Base course, dry density)

$\mathrm{O}$ : Travel-type RI density measurement device (6-point average)

$\Delta$ : Stationary-type RI density measurement device (3-point average)

$x$ : Sand replacement (1 point)

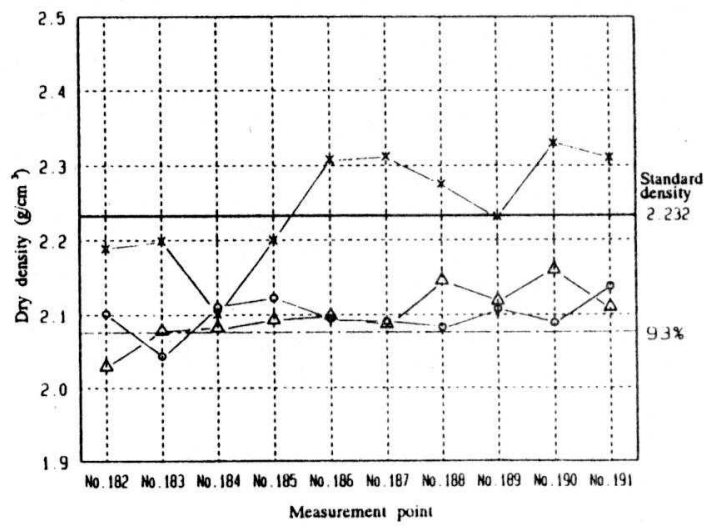

4.2 Binder course (Coarse-graded asphalt concrete) --- See Table 6 and Fig. 8

The standard deviation of measurement data of the travel-type RI device is around 0.04 $\left(\mathrm{g} / \mathrm{cm}^{3}\right)$, which is larger than that of the core density $\left(0.015 \mathrm{~g} / \mathrm{cm}^{3}\right)$, but is smaller if compared with the deviation of the sand replacement density, and its density is close to the core density absolute value, meaning that all coefficients are set appropriately. 
Table 6 Binder course (Coarse-graded asphalt concrete) test results Standard density: $2.405 \mathrm{~g} / \mathrm{cm}^{3}$

\begin{tabular}{|c|c|c|c|}
\hline & \multicolumn{3}{|c|}{ Wet density $\rho t\left(\mathrm{~g} / \mathrm{cm}^{3}\right)$} \\
\cline { 2 - 4 } & Travel-type RI & $\begin{array}{c}\text { Stationary-type } \\
\text { RI }\end{array}$ & Core density \\
\hline Average value & 2.295 & 2.317 & 2.352 \\
\hline $\begin{array}{c}\text { Maximum } \\
\text { value }\end{array}$ & 2.361 & 2.369 & 2.391 \\
\hline $\begin{array}{c}\text { Minimum } \\
\text { value }\end{array}$ & 2.215 & 2.286 & 2.329 \\
\hline $\begin{array}{c}\text { Compaction } \\
\text { degree (\%) }\end{array}$ & 95.4 & 96.3 & 97.8 \\
\hline $\begin{array}{c}\text { Standard } \\
\text { deviation }\end{array}$ & 0.037 & 0.027 & 0.019 \\
\hline $\begin{array}{c}\text { Coefficient of } \\
\text { variation (\%) }\end{array}$ & 1.61 & 1.17 & 0.81 \\
\hline
\end{tabular}

Fig. 8 Comparison between field density and travel-type and stationary-type RI density measurement results (Binder course, wet density)

O: Travel-type RI density measurement device (6-point average)

$\Delta$ : Stationary-type RI density measurement device (3-point average)

$x$ : Sand replacement (3-point average)

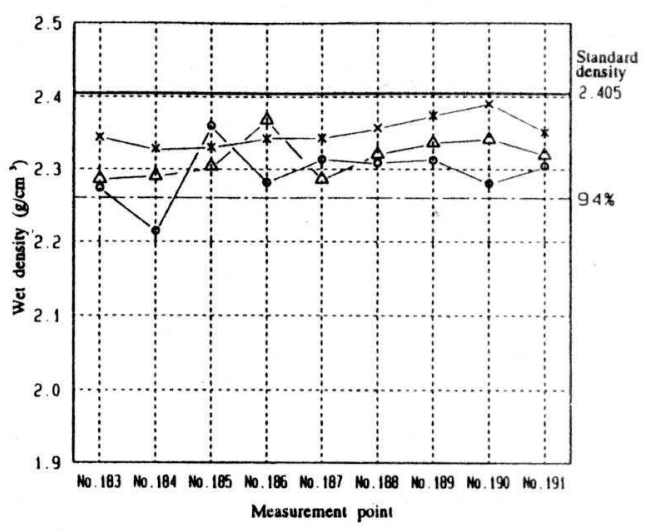

\section{SUMMARY}

The results of the test operations has shown the possibility of measuring the compaction degree in real time while recognizing the self-position of the travelling vehicle. This will enable optimum compaction by unskilled operators.

Furthermore, this will also enable drastic improvement of the present methods of field operation control and inspection and testing methods through storage of measurement data in IC cards.

\section{FUTURE PROBLEMS}

This system is still in the stage of function evaluation using prototype equipment, and the following problems must be solved before it is commercialized.

\subsection{Proving the reliability of RI measurement data}

As a result of a few test operations performed in the past, correction coefficients have been established for three (3) kinds of materials, namely, base course material, hot asphalt mixture and asphalt concrete existing in place. However, large volumes of data have not yet been accumulated for application to all work sites. It is necessary that in the future the reliability of measurement data be confirmed and improved by increasing the volume of data, including reviewing the coefficients established so far.

From the aspect of reliability, if the standard deviation is considered as the index of dispersion, it is better than that of the sand replacement density; however, that of travel-type RI measurement is still inferior to that of core density. 


\subsection{Accuracy of the self-position detection system}

Self-perfecting type vehicle position detection is performed by only three(3) sensors installed on the body of the roller, which is a travelling vehicle. Higher accuracy of position detection can be obtained if a fixed station is provided at a location other than on the roller body, but it will require more labor for installation and will increase the price, etc.,. which is why the present method was adopted.

In addition, there is the problem of self-position detection error, as seen in the test operation, due to unexpected behavior such as sideways slipping of the roller. Further, errors are caused by the temperature drift of the gyro of the optical fiber gyro now used in detection of bearings.

When self-position detection errors are accumulated, the position of the vehicle on the roller compaction map may be shown erroneously at a wrong point in a wrong grid block so that the roller compaction data cannot be correctly measured and displayed. This phenomenon took place as the unit grid size was as small as $10 \mathrm{~m}$ (Y-axis), $\times 1.4 \mathrm{~m}$ (X-axis) and in such a case a small error may generate such phenomenon. If this phenomenon occurs, condition setting must be redone. Therefore, improvement of the application method is being planned including enlargement of the grid block size as well as accuracy improvement.

\subsection{Operational problems}

The unit grid size for each data was set as small as $10 \mathrm{~m} \times 1.4 \mathrm{~m}$ for the purpose of obtaining as many data as possible for function evaluation, and accordingly the measuring travel speed was set at $1 \mathrm{~km} / \mathrm{h}$. However, this has resulted in an imbalance between the roller speed and the asphalt paver working speed.

Since the field density measurement frequency in Japan is now based on a unit grid block of $1,000 \mathrm{~m}^{2}$, improvements are now in progress including enlargement of the unit block size for practicability and the increase of the measurement travel speed to gain a working speed balance between the roller and the asphalt paver.

\subsection{Others}

From the viewpoint of compaction work optimization, the variable vibration generation mechanism capable of controlling the compaction force, as mentioned in Para. 2.1 above, is not exactly used to its best advantage.

Papers concerning methods to seek the optimum vibration frequency (to act as the vibration generating force) from the ground rigidity have been published; therefore by relating the results of those researches to our study, better results from this development project may
be expected in the future.

\section{REFERENCES}

1. "Development of Sensor-Utilizing-Type Paving System", Nakamura, Kiriyama and Mori. Civil Engineering Journal, Vol. 35, No. 9 (1993).

2. "Sensor-Utilizing-Type Paving Systems", Kiriyama. Public Works Construction, Vol. 36, No. 3 (1995).

3. "Soil Evaluation Method in Vibratory Compaction and Its Application to Automated Work Performance", Fujiyama and Tateyama. Terramechanics, No. 15 (1995). 